\title{
Fatigue Analysis of Steel Jacket Platform in Shallow Water Depth in the Gulf of Guinea
}

\author{
Adekola B. Adeyemi \\ Offshore Technology Institute, University of Port Harcourt, Rivers State, Nigeria \\ Tobinson A. Briggs (Corresponding author) \\ Mechanical Engineering, University of Port Harcourt, Rivers State, Nigeria \\ E-mail: tobinson.briggs@uniport.edu.ng
}

\begin{abstract}
This work investigates the fatigue life of a steel jacket installed at a water depth of $22 \mathrm{~m}$ in the Gulf of Guinea, both deterministic and spectral analysis was done using the Bentley SACS software. Wave data was collected every 3 hours for seven years resulting in 20440 sea states. The analysis was carried out using industry codes and standards for critical inspectable and non-inspectable members. The result of the analysis was obtained for 50 modal shapes, and the mass participation factors show the highest vibration at the mode shape of 2 . The fatigue life of the joint was determined for a life of 50 years and applying the factor of safety of 5; the spectral analysis shows that none of the members investigated to meet the fatigue life of 250 years. However, the deterministic analysis shows some members that meet the fatigue life of 250 years. The analysis was also conducted for the piles both above and below the mud line, and the spectral and deterministic analysis show that the piles meet a fatigue life of 500 years using a factor of safety of 10. It was concluded and recommended that the joints on the jacket that do not meet the fatigue life should be rewelded and inspected for structural integrity. Also, the result shows that the spectral analysis is more detailed than the deterministic analysis.
\end{abstract}

Keywords: jacket, fatigue analysis, Gulf of Guinea, SACS, spectral analysis, deterministic analysis, fatigue damage.

DOI: $10.7176 / \mathrm{ISDE} / 11-3-01$

Publication date: April $30^{\text {th }} 2020$

\section{Introduction}

With the continuous increase in the world population, the demand for energy has been on the rise. The estimation of the world energy demand is said to increase by $70 \%$ over the next 30 years, basically because of the increase in population (Osalusi, 2010). This rise in energy demand has resulted in the depletion of onshore reserves as many oil wells were drilled for more oil, this and other factors like government incentives for offshore exploration via reduced tax and little or no royalty is the reason for oil and gas exploration in the offshore environment (Vann, 2016). According to Chandrasekaran (2015), to carry out oil and gas exploration in the offshore environment, certain structures must be installed to support both equipment and workers. Offshore structures are categorised based on their support with relation to the seabed as; fixed platform and floating platform. Due to the circumstances of the environment in which these structures are to be installed, the design of these structures are usually rigorous and numerous factors are put into consideration. Offshore structures are subjected to both static loads and dynamic loads. The static loads are easily predicted and are adequately accounted for during design; therefore, static loads are not a problem (Chandrasekaran, 2015).

The dynamic loads, on the other hand, may not be easily predicted, hence the need to understand the various dynamic loads which offshore structures experience in their operating environment. The dynamic loads acting on an offshore structure include; wave, wind, current, earthquake, ice, blast, mass, damping, live loads, impact loads. In the analysis of the effect of environmental loads on offshore structures, there are many uncertainties, and the determination of these uncertainties is crucial to the safety of the offshore platform. One of these uncertainties is the modelling of the wave loads; ocean waves are irregular, Non-linear and Non-directional, especially those resulting from Hurricanes (Mirzadeh, Kimiaei, \& Cassidy, 2016).

The nature of wave loads is such that it is cyclic and repetitive, and the continuous impact of such loads on an offshore structure results into fatigue. According to the works of (Rohith \& Jayalekshmi, 2017) wave loads plays a significant role in fatigue failure due to their continuity in time and random sequence, as being tiny, moderate and sometimes catastrophic. The resultant of their failure occurs in areas of welded tubular joints. The majority of mechanical failure in engineering structures are due to fatigue (Habibi et al., 2012). Hence it is pertinent to do a fatigue assessment of new and existing offshore structure and estimate the time of failure of an offshore structure. A design engineer is faced with the task to reduce cost, reduce risk and add value to any project he finds himself, hence increasing the safety, serviceability and fatigue life of an offshore structure is of great interest to an offshore engineer (Moharrami \& Tootkaboni, 2014). 


\section{Design for Fatigue}

In the design of offshore jacket structures, with the design focus against fatigue, the choice of materials selection is of great importance. As pointed out by (Salama et al., 2017) materials are designed to withstand the combination of the different operating loads without going above their ultimate strength, instability condition or fracture limits. Hence, safety factors are usually included in the design to account for uncertainties associated with loadings, analysis and material performance. The several material's parameters are generally required to perform the proper material selection and design. These materials include; Yield strength, Ultimate strength, Elongation to failure, Reduction in area, Fracture toughness, Elastic modulus, Crack growth rate, Fatigue S-N curve.

Generally, there are two methods used in the design of structures for fatigue, and they include

a) S-N curve approach

b) Fracture Mechanics approach

\subsection{S-N curve in design for fatigue}

An S-N curve is a graph of the magnitude of alternating stress against the number of cycles to failure for a given material. S-N curves were developed by a German scientist known as August Wholer during the outcome of the event of an 1842 train crash in Versailles, France. According to the report, the axle of the locomotive failed under repeated "low level" cyclic stress of everyday usage on the railroad (Bandara, Siriwardane, Dissanayake, \& Dissanayake, 2015). In the quest to obtain any fatigue life prediction under variable amplitude loads, the fatigue response of the material under constant amplitude fatigue is required (Passipoularidis \& Brøndsted, 2009). For example, there are doubts that for composite materials that there is no fatigue limit (Haarman, Mulders, \& Vassiliadis, 2017), only a few fatigue test can be performed at stress levels usually exceeding the actual fatigue loads to be encountered during operation. Also, an adequate model for extrapolating or interpolating fatigues lives at any stress level must be assumed.

$\mathrm{S}-\mathrm{N}$ curves define the fatigue response of a material. The equation chosen for the S-N curve is significantly affecting life prediction under variable amplitude fatigue, as shown by the sensitivity analysis performed in (Nijssen, 2006). The fundamental way to derive an S-N curve is through linear regression on fatigue life data; the most commonly used relation is the following logarithmic (Log-Log ) equation (10). A straight line can represent it in the $\log (\mathrm{N})-\log \left(\sigma_{\max }\right)$ space;

$$
\sigma_{\max }=b \cdot \log (N)+K
$$

Mandell et al. (Mandell, Samborsky, Wahl, \& Sutherland, 2003) presented a three-parameter based on the one that was earlier proposed by Epaarachchi in his work (Epaarachchi \& Calausen, 2003) formulating an S-N curve flat at low cycles, steeper at medium and less steep at high cycles;

$X_{o}-\sigma_{\max }=\alpha \sigma_{\max }\left(\frac{\sigma_{\max }}{X_{O}}\right)^{b}\left(N^{c}-1\right)$

$\sigma_{\max }=k\left[\left(-\ln R(N)^{\frac{1}{\alpha_{f} b}}\right)\right] N^{\frac{1}{b}}$ Where $\mathrm{a}, \mathrm{b}, \mathrm{c}$ are fitting parameters while $\mathrm{Xo}$ is the ultimate strength of the material obtained at a strain rate similar to that of the fatigue test. Several tests were performed at various stress levels, and each data set is fitted to a Weibull distribution. Their respective characteristics of life normalise the experimental fatigue lives at each stress level, and the resulting population is also assumed to follow a Weibull distribution. The latter has a shape parameter of derived using maximum likelihood estimators. The S-N curve equation is finally;

$$
\sigma_{\max }=k\left[\left(-\ln R(N)^{\frac{1}{\alpha_{f}^{b}}}\right)\right] N^{\frac{1}{b}}
$$

The parameters $\mathrm{K}$ and $\mathrm{b}$ are derived through the fitting of a $\log -\log \mathrm{S}-\mathrm{N}$ formulation to the $\sigma_{\max }-$ characteristics life data points at the corresponding stress level.

\subsection{Fracture mechanics in design for fatigue}

Fracture mechanics is an aspect of mechanics that is focused on the study of the propagation of cracks in materials. It uses principles of solid analytical mechanics to determine the driving force on a crack and those of experimental solid mechanics to characterise the material's resistance to fracture. For a good number of structures, the major portion of the fatigue life is expended in propagating a crack from an existing flaw, that is, only the fatigue crack propagation life needs to be determined. A critical component in fracture approach is the parameter describing the stress field around the advancing crack tip.

In the works of (Donzella \& Petrogalli, 2010), they developed a fatigue limit approach for rolling contact based upon the fracture mechanics concept that avoidance of fatigue can be guaranteed if internal or early nucleated cracks are not able to grow. They formulated a failure assessment diagram to indicate whether a component was operating in a safe region or not. Concerning Elastic Fracture Mechanics (LEFM), the stress intensity factor was used when the nominal stress versus strain response is substantially elastic. However, when the plasticity effect is considered, various parameters have been proposed, among which crack tip opening displacement is the most 
commonly used in Elastic-Plastic Fracture Mechanics. Crack propagation life calculation is carried out from a specific initial crack size to a final crack size at failure, which may be determined from the material fracture toughness. However, several parameters are difficult to determine in practice, especially the initial crack size and shape. The shortcomings of the LEFM is that it is not accurate for short cracks, usually less than $1 \mathrm{~mm}$.

\section{Recent Development in Fatigue Analysis}

The increasing concept of fatigue analysis and fatigue behaviour of platforms did not occur due to the increasing number of life extension of offshore structures alone as fatigue was initially attributed to structures. The concept of fatigue began in the '19th century' during the industrial revolution (Schijve, 2009), going in-depth it was first recognised as a 'fracture phenomenon' which occurs when a large number of the load cycle, a unit load of the equal magnitude would not cause any harm.

3.1 Palmgren-miner rule

$\sum_{i=1}^{N} \frac{D_{i}}{D}=1$ According to ISO (2007), the prediction and estimation of fatigue damage are essential in the design of offshore fixed platforms. When a material is under the influence of repeatedly applied loads or cyclic loading, there is a localised structural deformation that occurs in the material, such deformation is known as Fatigue damage, and it is due to the fatigue loading. Fatigue loading is primarily the type of loading which result in cyclic variations in the applied stress or strain on a component. This loading leads to cumulative fatigue damage (Fatemi \& Yang, 1998). In 1945, miner expressed this concept in a mathematical form (Miner, 1945)consider a body that can endure only a certain amount of damage $\mathrm{D}$, if that body experience damages $D i$ from $N i$ sources, according to Palmgren-miner rule we might assume that 'failure' will occur if

$\sum_{i=1}^{N} \frac{D_{i}}{D}=1$

Where the ratio of $D i / D$ is the fractional damage received from the ith source. A case was presented by (Caglayan, Ozakgul, \& Tezer, 2009) where the estimation of fatigue damage was done based on Palmgren-miner's rule. A numerical procedure to predict the fatigue life of a bridge was developed; it was observed that damage increases at each stress range considered.

A significant shortcoming of the Palmgren-Miner rule is that it does not put into consideration order effects, i.e. the order in which loads are applied makes no variance in this rule. Sequence effects are indeed observed in many cases. A second downside is that the Palmgren-Miner rule says that the damage accumulation is not dependent on stress level.

Within the framework of the Palmgren-miner theory, two approaches to fatigue analysis are currently in use; (i) Spectral (or Statistical) fatigue analysis and (ii) Deterministic fatigue analysis.

\section{MATERIALS AND METHODS}

4.1 Theoretical Background

Environmental loads act on offshore structure steel jacket in general; however, steel jackets installed in a shallow water depth of $22 \mathrm{~m}$ are predominantly affected by wind loads, current and wave loads (Osalusi, 2010). Due to the intermittent nature of the environmental loads, they cause cyclic stress in the jacket structure, which in turn leads to fatigue.

\subsection{Wind loading}

Wind loading of offshore structures is caused by a complex fluid-dynamics phenomenon, which is generally arduous to calculate with high accuracy. The net pressure can determine the wind force on a plane orthogonal to the wind flow direction in the expression below;

$$
P w=\frac{1}{2} \rho_{a} C_{w} V^{2}
$$

It is pertinent to know that the mass density of air increases due to the water spray (splash) up to a height of $2-20 \mathrm{~m}$ above the MSL. Hence, the total wind-induced force on the tubular structure is given by;

$$
F_{w}=P_{w} A
$$

the wind has two components: (i) mean wind component (which is the static component) and (ii) fluctuating, gust component (which is a dynamic component). The gust component is generated by the turbulence of the flow field in all three spatial directions. The wind velocity is given as

$$
V(t)=\bar{v}+v(t)
$$

The spatial dependence of the mean component of the velocity is only through the vertical coordinate, while $v(t)$ is homogeneous in both space and time. The Wind force that is in the directions parallel (drag force) and normal to the wind direction (lift force) is given by;

$F_{D}=\frac{1}{2} \rho C_{D} \overline{\mathrm{v}}_{z} A \quad F_{D}=\frac{1}{2} \rho C_{D} \overline{\mathrm{v}}_{Z} A$ 
$F_{L}=\frac{1}{2} \rho C_{L} \bar{v}_{z} A \quad F_{L}=\frac{1}{2} \rho C_{L} \bar{v}_{Z} A$

Wind spectrum above water surface is given by $1 / 7^{\text {th }}$ power law, which is

$v_{z}=V_{10}\left[\frac{z}{10}\right]^{\frac{1}{7}} \quad v_{z}=V_{10}\left[\frac{z}{10}\right]^{\frac{1}{7}}$

\subsection{Wave Loading}

Waves are generated by the action of wind forces acting on the seawater. Sea surface waves can be represented by a combination of regular waves of different magnitude and wavelength and from different directions. The sea surface elevation expresses water particle kinematics of regular waves by various waves theories. Amongst all the theories, Airy's wave theory is mostly used because it assumes linearity between the kinematic quantities and the wave height, which makes the wave theory simple. Airy's theory assumes a sinusoidal waveform of wave height $(\mathrm{H})$, which is small in comparison with the wavelength $(\lambda)$ and water depth $(\mathrm{d})$ as given below

$$
\begin{aligned}
& \eta(x, t)=\frac{H}{2} \cos (k x-w t) \quad \eta(x, t)=\frac{H}{2} \cos (k x-w t) \\
& k=\frac{2 \pi}{\lambda} \mathrm{o}(x, t)=\frac{\omega H}{2} \frac{\cosh (k y)}{\sinh (k d)} \cos (k x-\omega t) \quad k=\frac{2 \pi}{\lambda} \\
& \mathrm{\textrm {u }}(x, t)=\frac{\omega H}{2} \frac{\cosh (k y)}{\sinh (k d)} \cos (k x-\omega t) \\
& \grave{v}(x, t)=\frac{\omega H}{2} \frac{\sinh (k y)}{\sinh (k d)} \sin (k x-\omega t) \\
& \dot{v}(x, t)=\frac{\omega H}{2} \frac{\sinh (k y)}{\sinh (k d)} \sin (k x-\omega t) \\
& \ddot{\mathrm{u}}(x, t)=\frac{\omega^{2} H}{2} \frac{\cosh (k y)}{\sinh (k d)} \sin (k x-\omega t) \\
& \ddot{\mathrm{u}}(x, t)=\frac{\omega^{2} H}{2} \frac{\cosh (k y)}{\sinh (k d)} \sin (k x-\omega t) \\
& \ddot{v}(x, t)=-\frac{\omega^{2} H}{2} \frac{\sinh (k y)}{\sinh (k d)} \cos (k x-\omega t) \quad \ddot{v}(x, t)=-\frac{\omega^{2} H}{2} \frac{\sinh (k y)}{\sinh (k d)} \cos (k x-\omega t)
\end{aligned}
$$

Airy's theory is valid up to mean sea level only. However, because of the variable submergence effect, the immersed length of the members will be continuously changing. Based on depth relative to their wavelength, ocean waves are grouped as shallow, intermediate and deep water as follow;

a) Shallow water: $\mathrm{h}<\lambda / 20$, phase speed depends only on water depth

b) Intermediate water: $\lambda / 20<\mathrm{h}<\lambda / 2$, phase depends on water depth and period of wave

c) Deep water: $\mathrm{h}>\lambda / 2$, phase speed is independent of water depth.

Wave spectrum describes the wave energy distribution of different frequencies of a sea state. Different wave spectrum formula has been proposed but the spectrum formula to use an instance depends on the wave environment frequency characteristics. In the case of the North Sea, the Joint North Sea Wave Project (JONSWAP) spectrum is recommended. However, in the case of the Gulf of Guinea, the same spectrum is also used. JONSWAP spectrum is a modified form of PM spectrum and it is normally used in the reliability analysis. This spectrum is applicable only for limited fetch, and it is recommended for the winter storm waves of the North Sea. The JONSWAP spectrum is expressed as:

$S^{+}(\omega)=P M \times \gamma^{\alpha(\omega)}=\left(\frac{\bar{\alpha} g^{2}}{\omega^{5}}\right) \exp \left[-1.25\left(\frac{\omega}{\omega_{o}}\right)^{-4}\right] \gamma^{\alpha(\omega)}$

The peakedness parameter $\mathrm{V}$ can be expressed as shown below;

$\gamma=\left\{\begin{array}{c}5 \\ \exp \left[5.75-1.15\left(\frac{T_{p}}{\sqrt{H_{s}}}\right)\right] \text { for } T_{p} / \sqrt{H_{s}} \leq 3.6 \\ \text { for } T_{p} / \sqrt{H_{s}}>3.6\end{array}\right.$

The modified Philips parameter $\bar{\alpha}$ is given as

$$
\bar{\alpha}=0.00325 H_{s}^{2} \omega_{o}^{4}[1-0.287 \ln (\mathrm{\gamma})]
$$

$H_{s}=4 \sqrt{m_{o}}$ is the wave height and $\mathrm{V}$ varies from 1 to 7 .

$a(\omega)=\exp \left[-\frac{\left(\omega-\omega_{o}\right)^{2}}{2 \bar{\alpha}^{2} \omega_{o}^{2}}\right]$

\subsection{Wave Data}

The wave data used for this work was collected for 20mins every 3hours for seven years, given a total of 20440 sea states. The sea state is defined by significant wave height, significant wave period, peak period and wave direction. Data collection is carried out by visual investigation and instrumental observations by buoys, radars, lasers and satellites. In the short term, the sea state is assumed to zero mean ergodic gaussian processes and can be defined adequately by a wave spectrum. The JONSWAP spectrum is used for the analysis of this model. In the long term, the variation of sea state is slower than the short-term fluctuations and is often approximated by a series of stationary nonzero-mean Gaussian process (Chandrasekaran, 2015).

The wave scatters data will be used in the structural analyses as this represents the long-term wave statistics. Stress transfer functions are calculated from wave analysis performed. Typically, 20 to 60 waves of constant 
steepness should be used with more waves concentrated near the natural period of the structure. Wave frequencies used to evaluate transfer functions are selected, taking into account the guidelines according to (ISO, 2007).

4.5 Gravity loads

A summary of the gravity loads for the fatigue analysis is given in Table 1;

Table 1. Gravity Loads

\begin{tabular}{lll}
\hline Load Description & Analysis (kN) & Analysis (Tonnes) \\
\hline Equipment & 2280 & 232 \\
Topsides steelwork & 3960 & 404 \\
Jacket steelwork & 2596 & 264 \\
Jacket Sundry Steelwork & 473 & 48 \\
Total & 9309 & 948 \\
Piles above Mudline & 1475 & 151 \\
Risers & 432 & 44 \\
Total & 11216 & 1143 \\
\hline
\end{tabular}

The mass of the computer model is 1143 tonne. The added mass of the structure, including marine growth was as follows:

X-direction: 336 tonnes

Y-direction: 335 tonnes

Z-direction: 198 tonnes

\subsection{Computer Model}

An isometric view of the platform, as shown in figure 1.

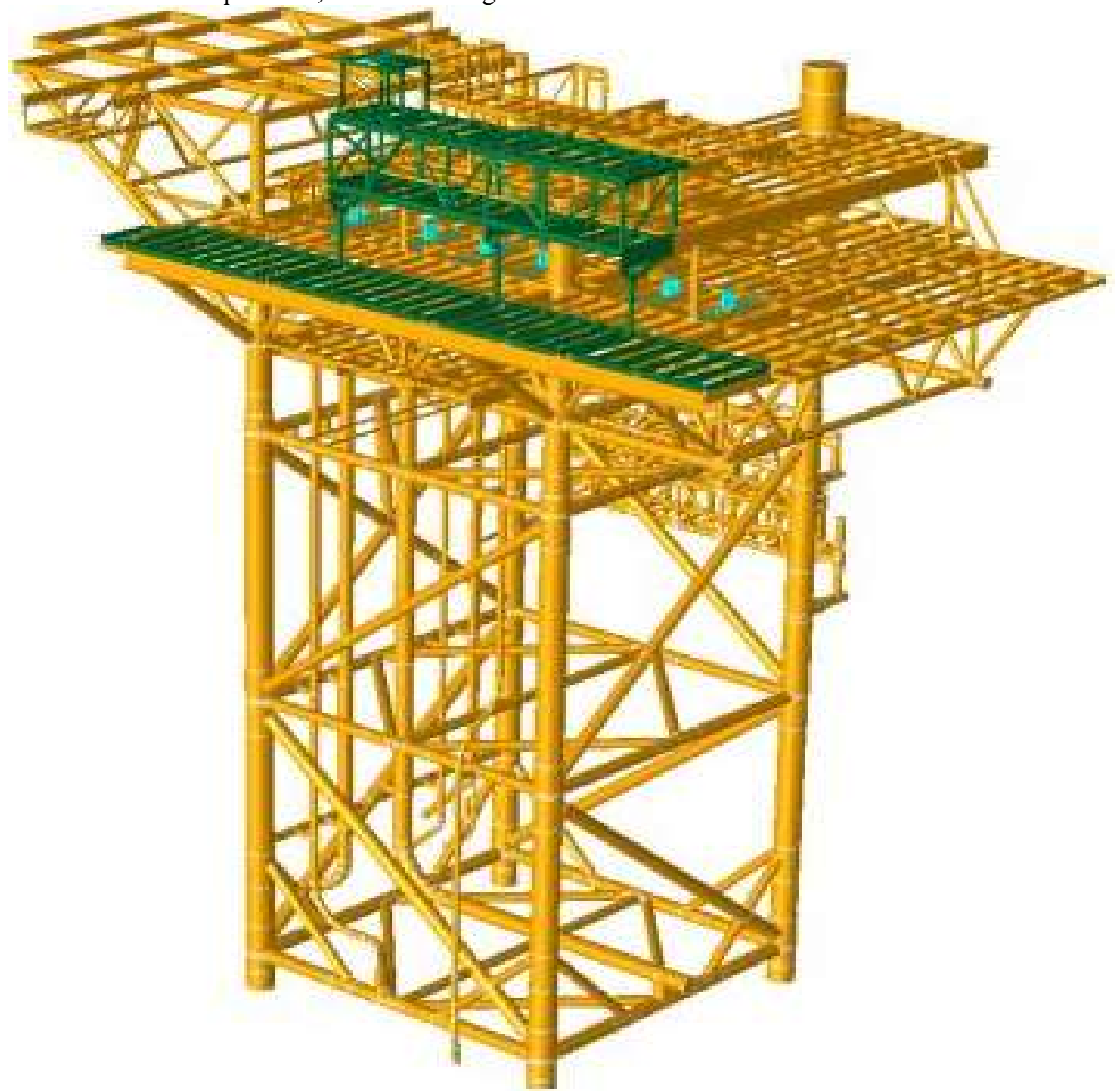

Figure 1. An isometric view of the platform 


\section{RESULTS}

5.1 Frequencies

The first three modes are Y-sway, X-sway and torsion, respectively. The remaining modes are not as clearly defined and include combinations of pure modes plus some local responses. Fifty modes were used in the analysis. A scatter plot of the mode against frequency and period is shown in Figure 2;

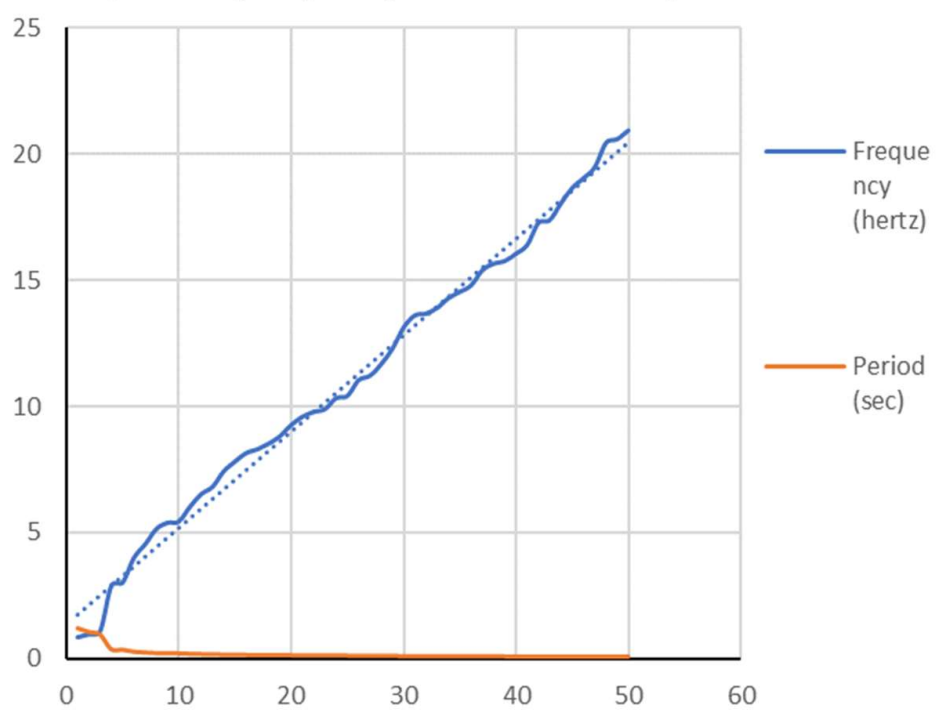

Figure 2. Mode Shape against Frequency and Period

5.2 Mass participation factors

In other to understand the response of the platform under the wave loading, the mass participation factor and the cumulative participation factor was determined for different mode shapes is determined. The plot of the mass participation factor and the Cumulative participation factor are shown in Figure 3 and 4, respectively.

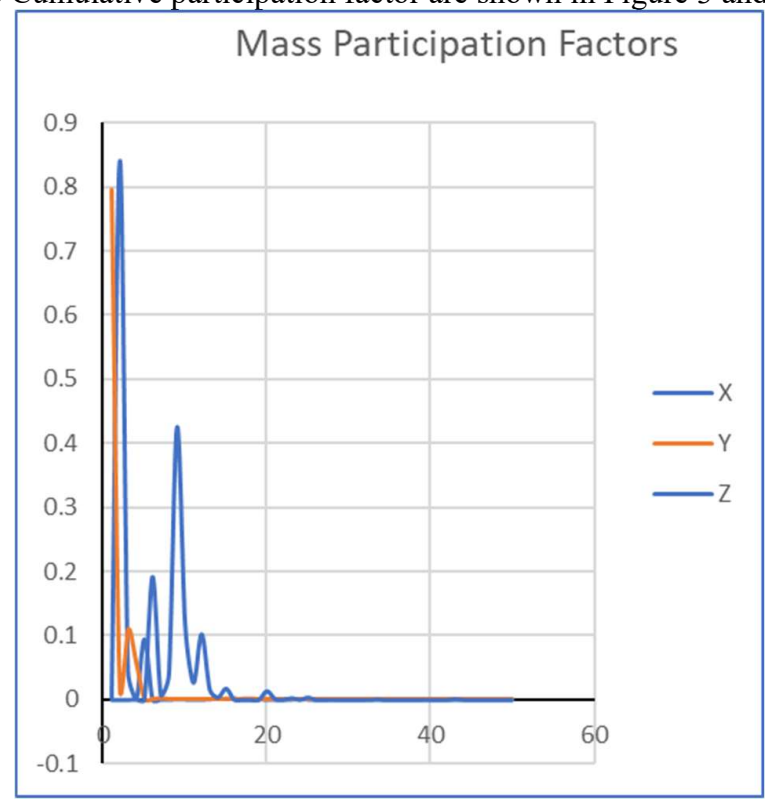

Figure 3. Mass participation factor against the modal shape 


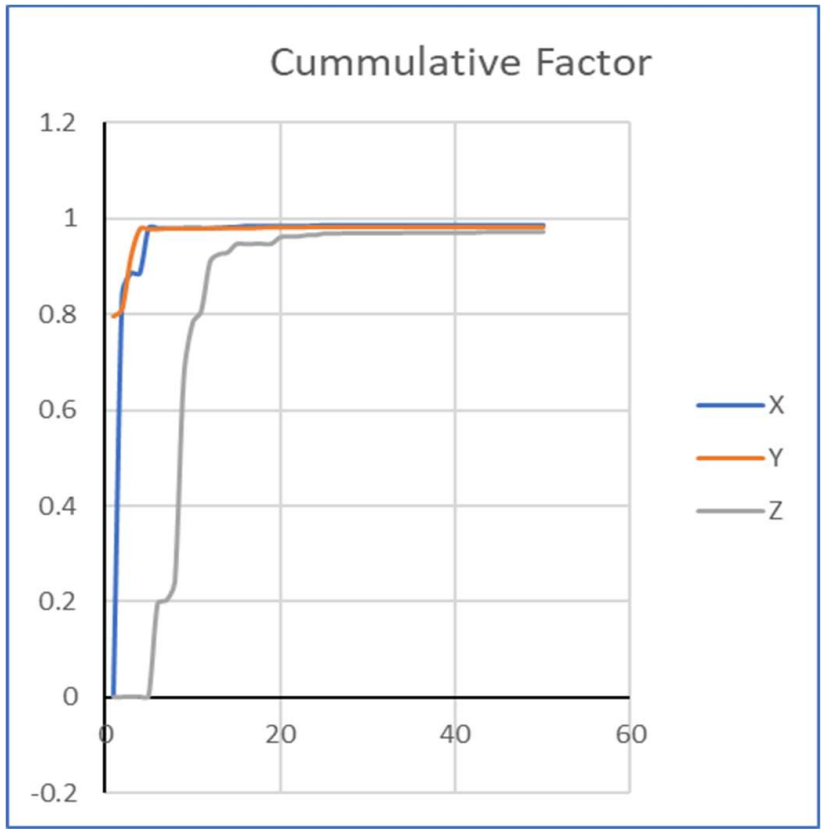

Figure 4. Cumulative factor against the modal shape

5.3 The fatigue life of joints

The minimum required fatigue lifetime equals the service lifetime multiplied with the Design Fatigue Factor (DFF), as depicted in Table 2. Items located in the splash zone shall be considered as non-inspectable, except the plan bracings in the top elevation of the jacket (at EL+6.000).

Table 2. Design Fatigue Factors

\begin{tabular}{|l|l|l|}
\hline & Inspectable & Non-inspectable \\
\hline Critical & 2 & 5 \\
\hline Non-Critical & 5 & 10 \\
\hline
\end{tabular}

Table 3 provides the lifetimes of the numbers with fatique lifetimes lower than 500 years. 
Table 3. Fatique life of Joints

\begin{tabular}{|c|c|c|c|c|c|}
\hline Fatigue Location & Joint & Spectral(years) & Deterministic(years) & Minimum Required(years) & Criteria \\
\hline Plan brace at El -21 & 1177 & 3.4 & 3601 & $50 * 5=250$ & critical and inspectable \\
\hline Plan brace at El -21 & 1104 & 3.7 & 4837 & $50 * 5=250$ & critical and inspectable \\
\hline $\begin{array}{l}\text { Jacket leg in bottom bay } \\
\text { of jacket at El }-15.5\end{array}$ & 1185 & 4.9 & 20885 & $50 * 5=250$ & critical and inspectable \\
\hline Plan brace at El -21 & 1176 & 6 & 16013 & $50 * 5=250$ & critical and inspectable \\
\hline Plan brace at $\mathrm{El}+6$ & 1165 & 7 & 0.2 & $50 * 5=250$ & critical and inspectable \\
\hline $\begin{array}{l}\text { Diagonal brace in top } \\
\text { bay of jacket at EL }-0.75\end{array}$ & 1191 & 24.3 & 5 & $50 * 10=500$ & critical and non-inspectable \\
\hline $\begin{array}{l}\text { Diagonal brace in top } \\
\text { bay of jacket at EL }-7.5\end{array}$ & 381 & 27.6 & 372416 & $50 * 5=250$ & critical and inspectable \\
\hline $\begin{array}{l}\text { Diagonal brace in top } \\
\text { bay of jacket at } E L+6\end{array}$ & 401 & 37.9 & 222118 & $50 * 5=250$ & critical and inspectable \\
\hline Plan brace at El -7.5 & 1109 & 52 & 1158078 & $50 * 5=250$ & critical and inspectable \\
\hline Plan brace at El -7.5 & $011 \mathrm{~B}$ & 68 & 29568000 & $50 * 5=250$ & critical and inspectable \\
\hline $\begin{array}{l}\text { Diagonal brace in top } \\
\text { bay of jacket at } E L+6\end{array}$ & 481 & 89.7 & 69 & $50 * 5=250$ & critical and inspectable \\
\hline $\begin{array}{l}\text { Diagonal brace in top } \\
\text { bay of jacket at } E L+6\end{array}$ & 419 & 109 & 207 & $50 * 5=250$ & critical and inspectable \\
\hline $\begin{array}{l}\text { Jacket leg in bottom bay } \\
\text { of jacket at El }-7.5\end{array}$ & 301 & 114 & 40742 & $50 * 5=250$ & critical and inspectable \\
\hline Plan brace at El -21 & 1113 & 130 & 41361 & $50 * 5=250$ & critical and inspectable \\
\hline Plan brace at El -21 & 1116 & 137 & 39607 & $50 * 5=250$ & critical and inspectable \\
\hline $\begin{array}{l}\text { Diagonal brace in } \\
\text { bottom bay of jacket at } \\
\text { EL - } 15.15\end{array}$ & $037 \mathrm{~A}$ & 274 & 3 & $50 * 5=250$ & critical and inspectable \\
\hline Plan brace at El -7.5 & 1108 & 315 & 12528 & $50 * 5=250$ & critical and inspectable \\
\hline Plan brace at El -7.5 & 1106 & 377 & 10418 & $50 * 5=250$ & critical and inspectable \\
\hline $\begin{array}{l}\text { Diagonal brace in } \\
\text { bottom bay of jacket at } \\
\text { EL - } 18.34\end{array}$ & 037B & 492 & 730423 & $50 * 5=250$ & critical and inspectable \\
\hline $\begin{array}{l}\text { Diagonal brace in } \\
\text { bottom bay of jacket at } \\
\text { El }-7.5\end{array}$ & 319 & 499 & 1 & $50 * 5=250$ & critical and inspectable \\
\hline
\end{tabular}




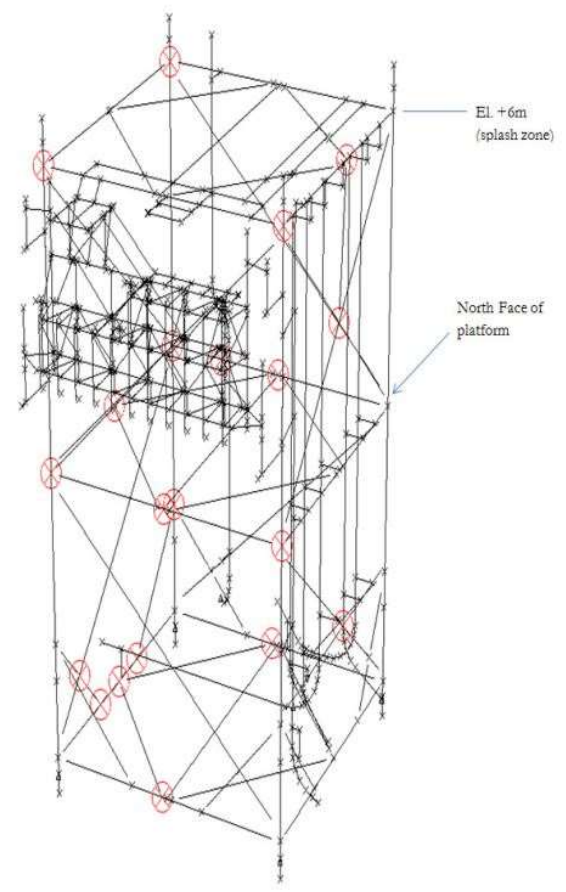

Figure 0. 3D View of Jacket Showing Joints (Circled) with Spectral Fatigue Lives Below 500 years

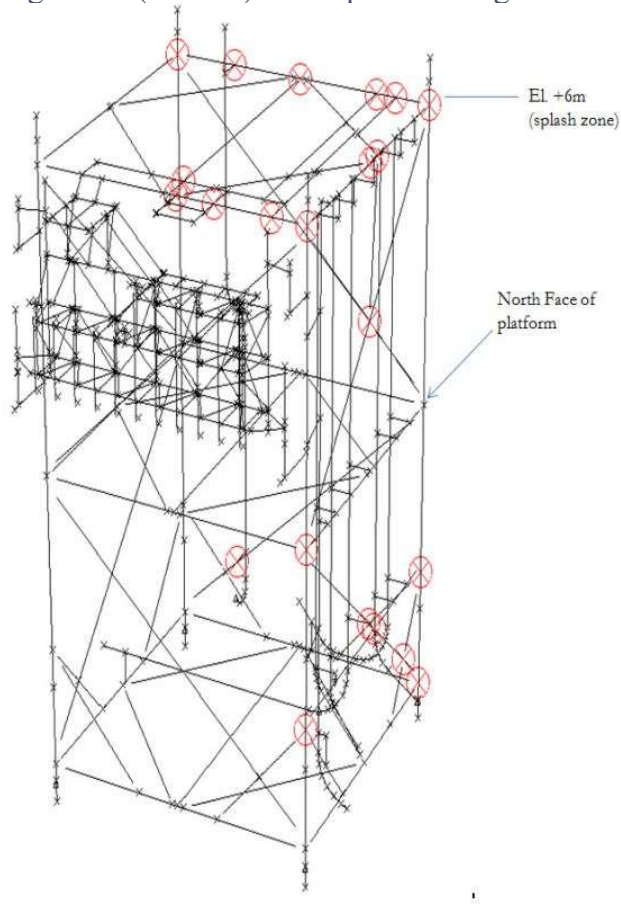

Figure 6. 3D View of Jacket Showing Joints (Circled) with Deterministic Fatigue Lives Below 500 years 5.3.1 Piles above the mud line

The fatigue lifetimes of the piles above the mud line was determined. The minimum required lifetime for the plots equals to 500 years. All members indicate a fatigue lifetime larger than 500 years. The ISO F2 S-N curve is applicable for the welds categorised as single-sided butt welds without backing strip. 


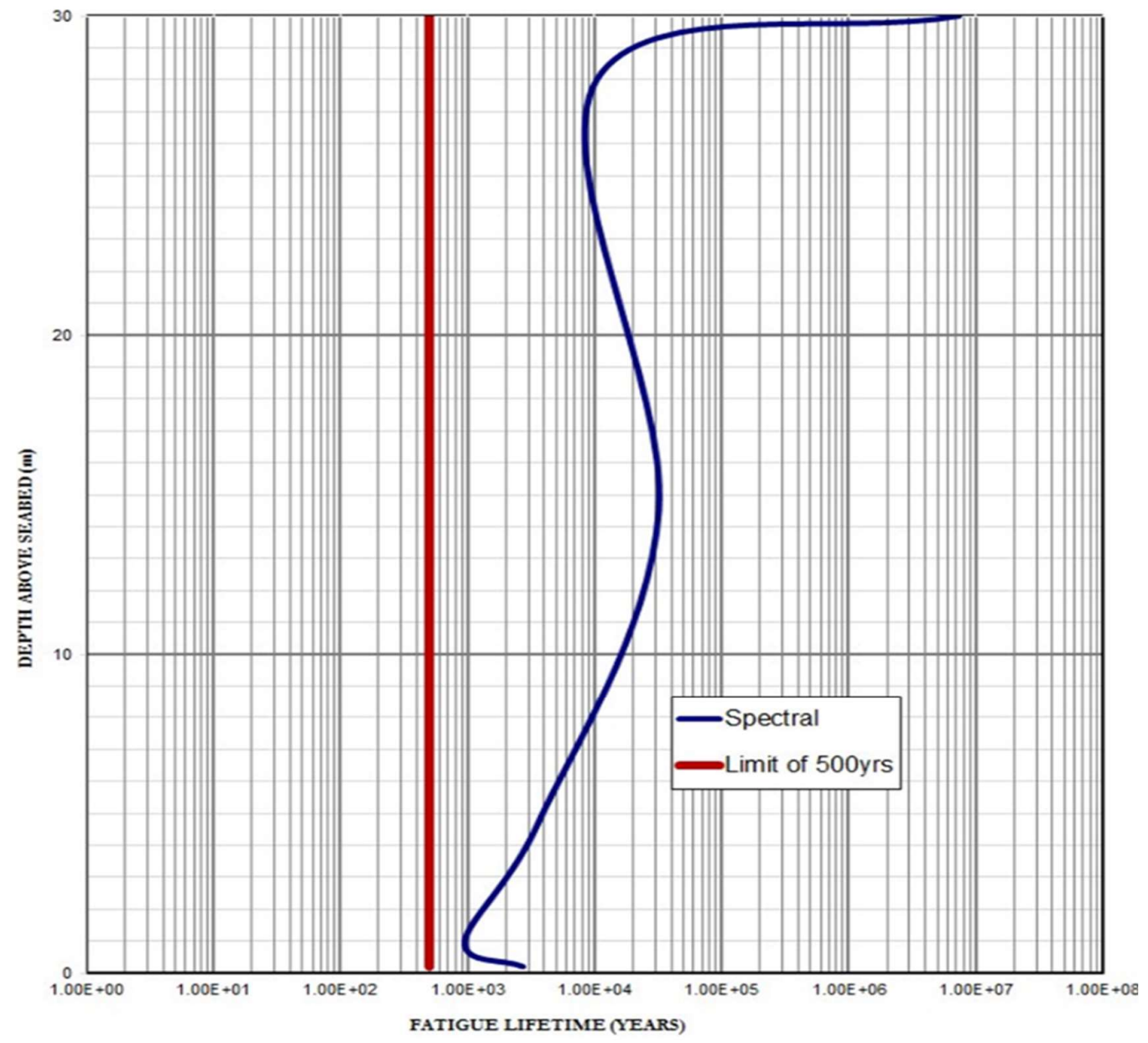

Figure 8. Fatigue Lifetime Vs Depth (below mud line)

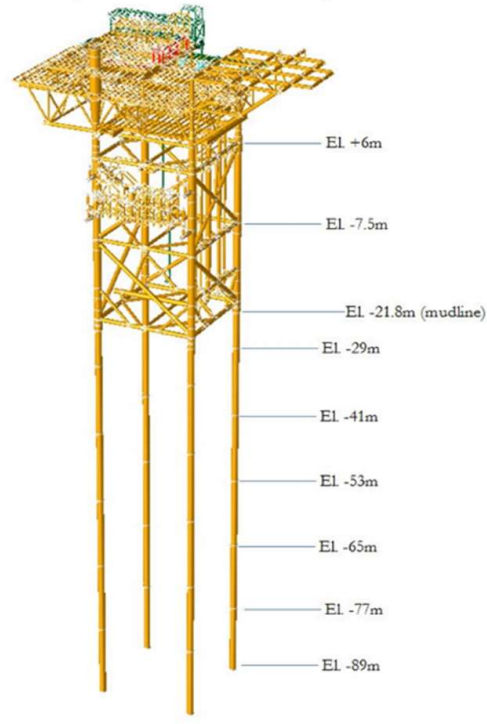

Figure 9. Isometric View of Platform showing risers below MudLine 
Table 4. Pile Fatigue due to Installation

\begin{tabular}{|c|c|c|c|c|c|c|c|c|}
\hline $\begin{array}{c}\text { Depth from } \\
\text { mudline }\end{array}$ & $\begin{array}{c}\text { Length } \\
{[\mathbf{m}]}\end{array}$ & $\begin{array}{c}\text { Blows/m } \\
{[\#]}\end{array}$ & $\begin{array}{c}\text { Total } \\
\text { blows [\#] }\end{array}$ & $\begin{array}{c}\text { Perc of } \\
\text { yield [\%] }\end{array}$ & $\begin{array}{c}\text { Yield } \\
{[\mathbf{M p a}]}\end{array}$ & $\begin{array}{c}\text { Stress } \\
\text { range } \\
{[\mathbf{M p a}]}\end{array}$ & $\begin{array}{c}\text { Nall } \\
{[\#]}\end{array}$ & DIN \\
\hline $0-23$ & 23 & 50 & 1150 & $50 \%$ & 345 & 172.5 & 14077 & 0.081 \\
\hline $23-67$ & 44 & 100 & 4400 & $50 \%$ & 345 & 172.5 & 14077 & 0.313 \\
\hline & & Total & 5550 & & & & Total & 0.394 \\
\hline
\end{tabular}

\section{Discussion}

For the Spectral fatigue analysis, the fatigue lifetimes of the jacket structure have been determined. The cut-off lifetime for the plots equals to 500 years. All members not indicating a lifetime on the plot inhibit a larger fatigue lifetime than 500yrs. About 20 joints have a fatigue life below 500 years, while about 8 of these joints have a fatigue life below 50 years, as shown in Figure 4. All members on the plots are considered primary structure except the existing riser supports and risers. Clamps are used for the additional riser, and therefore no fatigue is considered for these items.

The deterministic fatigue analysis did not give a better result compared to the spectral analysis in that the wave loads and the associated cyclic stresses are only due to the local wave loads rather than the dynamic response of the structure against waves. The accuracy of the deterministic analysis depends highly on the discretisation of the sea state, and any simplification will lead to erroneous estimation of response and fatigue damage. Most of the joints with fatigue lives less than 500 years are concentrated at the north face of the platform and an elevation of $+6 \mathrm{~m}$ (splash zone).

The total mass of the computer model is 1143 tonne, and the mass breakdown is shown in Table1; also, the effect of marine growth is considered in the analysis in terms of the added mass in the respective coordinate axis. The mode of vibration of a system is usually characterised by a modal frequency and a mode shape; the mode shape, however, is a specific pattern of vibration executed by a mechanical system at a specific frequency; hence, different mode shape will be associated with different frequencies, this can be seen in the plot shown in Figure 1 where the mode shape was plotted against frequency, the relationship is relatively linear with each mode shape having a unique frequency.

When the frequency of the dynamic load (wave loads) coincides with one of the natural frequencies of the structure, the structure undergoes a massive displacement and stresses, this phenomenon is known as resonance. One of the many questions that usually arise during Modal Analysis is "how do I know if a certain load will resonate with the structure". To answer this question requires the concept of Mass Participation Factor; this phenomenon gives the amount of system mass participating in a particular mode, which is the measure of the energy contained within each resonant mode. Figure 3 and 4 shows the plot of the mass participating factor against mode in the $\mathrm{X}, \mathrm{Y}, \mathrm{Z}$ directions, from the plot, it can be seen that the mass of the model in the $\mathrm{X}$ direction is more likely to cause a more massive displacement on the structure and also, this was highest when the mode was between 1 and 10

The chart in Figure 7 and Figure 8 shows a plot of depth (Both below and above) Mudline against fatigue Life, and it can be seen from the graphs that pile members exceed the 500 years requirement as the blue line did not cross the red line.

\section{CONCLUSION}

The analysis shows that the spectral analysis is accurate compared to the deterministic analysis and also the loadbearing members of the structure; the PILES meet the service life requirements of 500 years.

In general, based on the model predictions, it is concluded that some joints in the jacket structure of the platform, do not have a cognitive fatigue performance up to the target service life of the platform. This is evident by the low fatigue lives obtained in these joints. They do not meet the minimum required life of 250 years. However, all the joints of the piles above and below the mud line show a cognitive fatigue performance by exceeding the minimum required life of 500 years.

It is, therefore, recommended that the joint with lower fatigue lives below 250 years can be improved by strengthening, grouting, grinding, peening of weld toes (hammer peening, needle peening or ultrasonic peening) or replacing the braces and connections with new ones.

\section{References}

Bandara, C. S., Siriwardane, S. C., Dissanayake, U. I., \& Dissanayake, R. (2015). Developing a full range S-N curve and estimating cumulative fatigue damage of steel elements. Computational Materials Science, 5, 223 231. https://doi.org/10.1016/j.commatsci.2014.09.009

Caglayan, B. O., Ozakgul, K., \& Tezer, O. (2009). Fatigue life evaluation of a through-girder steel railway bridge. Engineering Failure Analysis, 1-10. https://doi.org/10.1016/j.engfailanal.2008.06.018 
Chandrasekaran, S. (2015). Dynamic Analysis and Design of Offshore Structures (Vol. 5). https://doi.org/10.1007/978-81-322-2277-4

Donzella, G., \& Petrogalli, C. A. (2010). A failure assessment diagram for components subjected to rolling contact loading. International Journal of Fatigue, 32, 256-268.

Epaarachchi, J. A., \& Calausen, P. D. (2003). An empirical model for fatigue behaviour prediction of glass fibrereinforced plastic composites for various stress ratios and test frequencies. Composite Materials Series, 34, 313-326.

Fatemi, A., \& Yang, L. (1998). Cumulative fatigue damage and life prediction theories: A survey of the state of the art for homogeneous materials. International Journal of Fatigue, 5, $225-234$. https://doi.org/10.1016/S0142-1123(97)00081-9

Haarman, M., Mulders, M., \& Vassiliadis, C. (2017). Predictive Maintenance 4.0: Predict the unpredictable.

Habibi, N., H-Gangaraj, S. M., Farrahi, G. H., Majzoobi, G. H., Mahmoudi, A. H., Daghigh, M., ... Moridi, A. (2012). The effect of shot peening on fatigue life of welded tubular joint in offshore structure. Materials and Design. https://doi.org/10.1016/j.matdes.2011.11.024

ISO, 19902. (2007). Petroleum and natural gas industries - fixed steel offshore structures. In International Standard (Vol. 17). Paris.

Mandell, J. F., Samborsky, D. D., Wahl, N. K., \& Sutherland, H. J. (2003). Testing and analsysis of low cost composite materials under spectrum loading and high cycle fatigue conditions. ICCM14, SME/ASC, 1811.

Miner, M. A. (1945). Cumulative damage in fatigue. American Society of Mechanical Engineers - Journal of Applied Mechanics, 16, 47-54. https://doi.org/10.1007/978-3-642-99854-6 35

Mirzadeh, J., Kimiaei, M., \& Cassidy, M. J. (2016). Effects of irregular nonlinear ocean waves on the dynamic performance of an example jack-up structure during an extreme event. Marine Structures, 49, $148-162$. https://doi.org/10.1016/j.marstruc.2016.05.007

Moharrami, M., \& Tootkaboni, M. (2014). Reducing response of offshore platforms to wave loads using hydrodynamic buoyant mass dampers. Engineering Structures, 81, 162-174. https://doi.org/10.1016/j.engstruct.2014.09.037

Nijssen, R. P. L. (2006). Fatigue Life Prediction and Strength Degradation of Wind Turbine Rotor Blade (TU DELFT). Retrieved from Faculty of aerospace engineering

Osalusi, E. (2010). Analysis of wave and current data in a tidal energy test site (Heriot-Watt University). Retrieved from http://www.ros.hw.ac.uk/handle/10399/2327

Passipoularidis, A. V. A., \& Brøndsted, P. (2009). FATIGUE EVALUATION ALGORITHMS : REVIEW Risø-RReport (Vol. 1740). Copenhagen: DTU publisher.

Rohith, T., \& Jayalekshmi, R. (2017). DETERMINISTIC AND SPECTRAL FATIGUE ANALYSIS OF TUBULAR JOINTS OF A JACKET PLATFORM. 8(11), 149-158.

Salama, M. M., Osalusi, E., Moharrami, M., Tootkaboni, M., Pedersen, P. T., Dong, W., ... Jayalekshmi, R. (2017). Materials for Offshore Applications. Handbook of Offshore Engineering, 1(1), 162-174. https://doi.org/10.15302/J-ENG-2015004

Schijve, J. (2009). Fatigue of structures and materials. In Fatigue of Structures and Materials. https://doi.org/10.1007/978-1-4020-6808-9

Vann, A. (2016). Offshore oil and gas development: Legal framework. In Federal Income From Crude Oil and Natural Gas: Issues and Options. 